\title{
An Experimental Study on Concrete Flat Slabs Prestressed with Carbon Fibre Reinforced Polymer Sheets
}

\author{
Yin Shen, ${ }^{1}$ Shaohui $\mathbf{L u},{ }^{2}$ and Fangyuan $\mathrm{Li}^{1}$ \\ ${ }^{1}$ Department of Bridge Engineering, College of Civil Engineering, Tongji University, 1239 Siping Road, Shanghai 200092, China \\ ${ }^{2}$ Liuzhou OVM Machinery Co., Ltd., Longquan Road, Liuzhou, Guangxi 545005, China \\ Correspondence should be addressed to Fangyuan Li; fyli@tongji.edu.cn
}

Received 30 June 2015; Revised 29 September 2015; Accepted 5 October 2015

Academic Editor: Stefano Sorace

Copyright (c) 2015 Yin Shen et al. This is an open access article distributed under the Creative Commons Attribution License, which permits unrestricted use, distribution, and reproduction in any medium, provided the original work is properly cited.

Carbon fibre reinforced polymer (CFRP) is currently used to reinforce buildings in civil engineering in the common forms of sheets, while the utilization efficiency of a CFRP materials greatly decreased when the CFRP material is directly bonded to the structure because of the lack of the effect of the exertion of a prestress. A paper spool-inspired anchoring method is proposed to overcome the shearing problem in the anchoring system through the friction between layers. Anchoring and jack-up tensioning devices for CFRP sheets are also designed and produced. A prestress is successfully applied to single and multiple CFRP sheets ( $80 \%$ tensioning strength is achieved), thus verifying the tensioning effect of the prestress. Based on these results, prestressed concrete flat slabs were designed with pretensioned CFRP sheets. The corresponding mechanical properties of the concrete flat slabs are tested to verify the feasibility of using CFRP sheets to apply a prestress. The results show that the uniformity of the fibre stress during the tensioning of the CFRP sheet is the key to the success of the application of the prestress.

\section{Introduction}

Fibre reinforced polymers (FRPs) have many advantages, such as high strength, low creep, moderate elastic modulus, and good corrosion resistance. Therefore, they can be used to replace the steel bars and prestressed steel bars in concrete structures and steel plates externally bonded to concrete for reinforcement. Since the 1960s, through research and development and engineering pilot projects, FRPs have been used in the construction, reconstruction, and reinforcement of bridges and buildings in the United States (US), Canada, Europe, and Japan [1].

FRPs are composed of high-performance fibres and binders. Based on the type of fibres used, common FRPs are categorized as glass fibre reinforced polymers, carbon fibre reinforced polymers (CFRPs), and aramid fibre reinforced polymers. CFRPs are high-tech products that have excellent properties, such as high specific strength, high specific moduli, high temperature resistance, high corrosion resistance, high fatigue resistance, high creep resistance, high electrical conductivities, high thermal conductivities, and low thermal expansion coefficients. CFRPs can be used both as structural materials to bear loads and as functional materials to perform their functional roles. Therefore, CFRPs have been developing rapidly in recent years and have been widely used in many fields, such as aeronautics, astronautics, the automobile industry, environmental engineering, chemical engineering, energy, traffic, building construction, electronics, and sports equipment. CFRPs are praised as the new material of the 21st century [2].

CFRP tendons are the FRP material used in concrete structures with the best prospects because CFRP tendons are regarded as the replacement for steel bars in steel reinforced structures. Currently, CFRP sheets and CFRP plates are used for structural reinforcement more commonly than other materials $[3,4]$. First, CFRP sheets and CFRP plates are relatively easy to produce. Second, repairing and reinforcing the existing structures worldwide represent a large guaranteed demand for CFRP sheets and CFRP plates, which will also help to maintain relatively low prices for CFRP sheets and CFRP plates for the foreseeable future. Hence, researchers from several countries have conducted studies on CFRP sheets and plates, which have contributed to the continuous improvement and perfection of the production 
processes [3,5]. According to the literature, 95\% of the CFRP sheets and plates are used to strengthen and reinforce existing structures worldwide, while CFRPs are directly used as structural materials only in trial experimental studies. Therefore, based on their price advantage, the utilization of the economy and excellent properties of fibre sheets or plates as well as the development of new applications of fibre sheets or plates have high potential economic value.

The steel plate bonding and reinforcement technique is commonly used to strengthen reinforced concrete (RC) structures. However, steel plates are heavy and difficult to transport; in addition, the cutting and moulding of steel plates are also relatively complicated. These shortcomings can be avoided by using fibre sheets or fibre plates, which are lightweight, easy to machine, and have a very high uniaxial tensile strength [6-9]. Since the 2000's First Symposium on Fibre Reinforced Plastic Concrete Structures, the research on the application of FRPs in civil engineering and construction in China has reached an unprecedented scale. Based on the requirements of the China Association for Engineering Construction Standardization, the National Industrial Building Diagnosis and Retrofit Engineering Technology Research Centre of China (the Central Research Institute of Building and Construction, the Ministry of Metallurgical Industry), the Sichuan Institute of Building Research, and other relevant units have jointly compiled the Technical Specification for Strengthening Concrete Structures with Carbon Fibre Reinforced Polymer Laminate (China Engineering Construction Standardization 146:2003) [10]. A new, revised version of this technical specification is currently being prepared.

CFRPs are brittle materials; therefore, it is necessary to consider the requirements of structural strain during the design process. The carbon fibres used in structures generally have a strain of $1.2-1.5 \%$, which is smaller than the strain in a steel strand (6\%); thus, such carbon fibres completely satisfy the basic requirements of structural deformation and cracking, and signs of structural damage or overloading can be observed. Similar to concrete, CFRP can also fail from creep rupture under sustained high-loading conditions. When the sustained load exceeds $75-80 \%$ of the ultimate tensile strength, the life of the CFRP will be affected [11-13]. Therefore, the long-term load on a steel tendon is limited to $50-60 \%$ of the tensile strength of the tendon under static loading conditions to reduce the permissible value of the prestress and the applicable sustained load. However, this limitation is not an obstacle during the design process because when the stress on CFRP tendon reaches $60 \%$ of the tensile strength of the CFRP tendon under static loading conditions or lower, the CFRP tendon still maintains its total tensile capacity, and the reserved $40 \%$ of the tensile strength can then be used for bending deformation and fatigue load after the initial stress occurs.

Even though high tensile strength and moderate elastic modulus CFRP tendons are suitable for prestress, CFRP tendons are still disadvantageous because they are heterogeneous and brittle. The heterogeneity may cause a CFRP tendon to easily fail when used to apply a prestress to an anchor. To date, no anchoring system has been developed that can ensure that CFRP tendons reach the optimal level of stress transfer [11, 14-17]. Therefore, developing an anchoring system that can ensure that CFRP tendons reach the optimal top stress transfer, that is, developing the anchorages required when using CFRPs as prestressing tendon material, has become one of the focuses of the research using CFRPs as prestressing tendons $[18,19]$. Therefore, combining the mature CFRP sheet material technique and the prestressing technique provides new application modes and ideas for CFRP materials and the prestressing technique, which is the research objective and goal of this study.

\section{Material and Methods}

2.1. Method for Applying a Prestress to a CFRP Sheet. If the rotation of a paper spool is hindered when the paper on the spool is pulled, the gap between the layers will be compressed, and the paper will be elongated during the process until the gap between layers is completely compressed. When pulling the paper, the pressure on the paper will gradually decrease if the layers of the paper are maintained in parallel. The balancing force to the pulling force is from both the tension on the topmost layer of the paper and the friction between the topmost layer of the paper and the layer of the paper immediately below the topmost layer of the paper. This way, the direct shearing on fibres that occur when using other anchoring methods, such as the anchoring method that uses clips, can be avoided, and the brittle failure of fibres can be avoided.

Inspired by these paper spools, in this study, CFRP sheet is clipped onto a cylindrical drum, and the CFRP sheet is then wound using the friction between layers $(T)$ to create tension in the CFRP sheet during the process while the corresponding length of the CFRP sheet continuously decreases. The anchoring force of the CFRP sheet material is the sum of the friction between the rotating drum and the CFRP sheet $(N)$ and the self-resistance $\left(T^{\prime}\right)$; that is, $T^{\prime}+\sum \tau=$ $T$ (Figure 1). The two layers of the CFRP sheet are the same, and there is adequate contact area between the two layers. Therefore, compared to traditional anchoring methods, such as the anchoring method that uses clips, the shearing force of the anchorage generated using this method is relatively dispersed and does not result in the failure of the fibres by shear forces.

Figure 1 summarizes the initial idea of this study. Experimentation is required to verify the feasibility of this idea. The authors of this study and the researchers at the OVM Research Centre on Prestress at Tongji University jointly designed the experimental frame. When designing the experimental frame, we considered the effect of the deformation of the steel drum used for winding the CFRP sheet on the prestress loss of the CFRP sheet and the jack-up construction time required to reach the curing age needed for the required strength of the concrete as well as how to overcome the eccentricity of the CFRP sheet relative to the rotating drum during the winding process. Tension is increased using jacks on both sides. The jack-up tension is checked using the pressure sensor located at the front of each jack. To perform the experiments, a rotating drum device is required. 


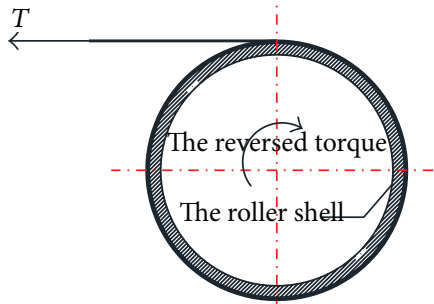

(a) Layout of roller with sheets

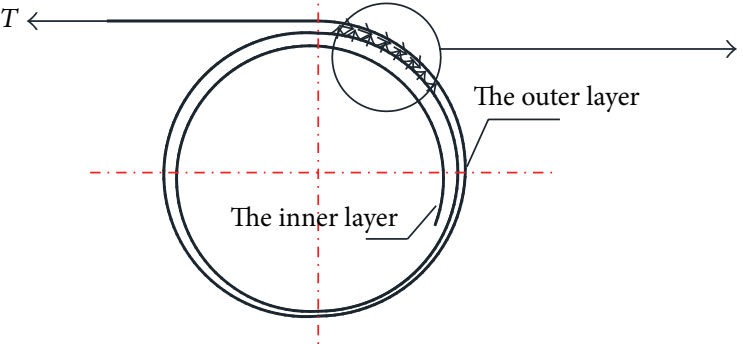

(b) Location of sheets

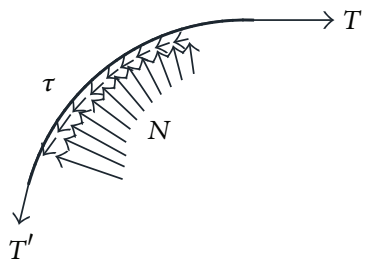

(c) Action between different layers

Figure 1: Diagram of the principle of the anchor tension.

The tension must also be measured to control the tension of the CFRP.

2.2. Material. The Tonggu CFRP sheets (model numbers CFC2-2 and CFC20-3) manufactured by Shanghai Yichang Industry Corporation were used as the experimental CFRP sheets. The detailed parameters of the CFRP sheets are summarized in Table 1.

\section{Experiments and Results}

There are two types of experiments that were completed. To verify the feasibility of the proposed method, tensioning tests on single and multiple CFRP sheets were conducted. Concrete flats with or without CFRP sheet prestressed were completed to verify the effectiveness.

\subsection{Experiment to Verify the Method to Get the Prestressing with CFRP Sheet}

3.1.1. Single CFRP Sheet. The trial winding test results show that the number of the winding layers has a relatively large impact on the tension in the CFRP sheet. In the initial stage of the winding process, there is friction between any two adjacent layers; however, when the CFRP sheet was subjected to an external force, only the outermost 2-3 layers are able to effectively provide friction. An excessive number of winding layers are detrimental to stress uniformity because an increase in the length error between two points results in an inconsistency between the extended lengths. In addition, an increase in the number of winding layers results in an increase in the winding thickness, which in turn renders the tensile deformation difficult to control. Therefore, it is concluded that the optimal number of winding layers is three to get the uniform stress. This conclusion also provides a compelling basis for saving CFRP sheet materials.

Figure 2(a) shows the winding process in which the CFRP sheet is wound onto the rotating drum on one side. Figures 2(b) and 2(c) show the manual pretension process performed before the CFRP sheet is unwound onto the rotating drum on the other side and the preparation before the final jack-up tension process, respectively. Figure 2(d) shows the process of clamping the CFRP sheet onto the rotating drum on the other side. Figures 2(e) and 2(f) show the bidirectional winding process and the check-up process before the jack-up process.
Following the tensioning scheme, an experiment is performed on one CFRP sheet using the fabricated tension device. Figure 3 shows the experimental effect. During the experiment, it was difficult to apply tension uniformly to all the fibres in the sheet material. Figures 3(a) and 3(b) show the results of the tensile failure of longitudinal fibres caused by nonuniform tension on one side and uniform tension on the other. The data in the figure show that nonuniform stress results in an excessive stress on local fibres, which results in the gradual failure of fibres at the cross section. By adjusting the loading speeds of the jacks on both sides, the horizontal position, and the initial winding state of the CFRP sheet material during multiple runs, a near-ideal stress condition is achieved (Figure 4).

Based on the parameters of the material provided by the manufacturer and considering the prestressing effect, the minimum jack-up tension is determined. The minimum control stress is set at 0.5 times that of the tensile strength. Considering the safety of the experiment, the maximum control value of the tensile stress is set at 0.8 times that of the tensile stress. Based on the determined minimum jackup tension, minimum control stress, and maximum control value of the tensile stress, the corresponding jack-up control forces are estimated (Table 2).

The tensioning control stress is measured thrice while test-running the jack-up tensioning frame. The results of the tests are 2,027 MPa, 2,684 Mpa, and 2,521 MPa, which correspond to $0.57,0.76$, and 0.71 times that of the tensile strength, respectively. Because the effect of the uniformity of the CFRP sheet is not considered, the tensioning control stress does not reach the expected value $\left(0.8 f_{y c}\right)$ in any of the three tests, and tensioning stops when the failure of local fibres occurs in all of the tests. Through constant adjustments, these possible unfavourable conditions are eliminated. Afterwards, the ultimate tensioning stress is tested thrice. The results show that the ultimate tensioning stress does not reach the tensile strength provided by the manufacturer in any of the tests; the local tensile failure of the CFRP sheet occurs instead. The results of the three tests show that the ultimate tensioning stress was $0.80,0.89$, and 0.87 times that of the tensile strength. These results have practical significance for the selection of the design value of the tensile strength of the CFRP sheet in application. 
TABLE 1: Specifications and parameters of the CFRP sheets used in the experiments.

\begin{tabular}{lccccc}
\hline $\begin{array}{l}\text { Product } \\
\text { thickness }\end{array}$ & $\begin{array}{c}\text { Carbon fibre } \\
\text { type }\end{array}$ & Tensile strength & Tensile elastic modulus & Elongation at fracture & Weight per unit area \\
\hline $0.12 \mathrm{~mm}$ & T-700-12K & $\geq 3500 \mathrm{MPa}$ & $220 \mathrm{GPa}$ & $1.8 \%$ & $300 \mathrm{~g} / \mathrm{m}^{2}$ \\
$0.17 \mathrm{~mm}$ & T-700-12K & $\geq 3500 \mathrm{MPa}$ & $220 \mathrm{GPa}$ & $1.8 \%$ & $100 \mathrm{~mm}$ \\
\hline
\end{tabular}

TABLE 2: List of the control parameters for tensioning.

\begin{tabular}{ll}
\hline Elastic modulus of the CFRP sheet & $E=220 \mathrm{GPa}$ \\
Tensile strength & $f_{y c}=3,550 \mathrm{MPa}$ \\
Cross section & $A_{f}=0.12 \mathrm{~mm} \times 100 \mathrm{~mm}=12 \mathrm{~mm}^{2}$ \\
Minimum control tensioning stress & $f_{\min }=0.5 f_{y c}=0.5 \times 3,550=1775 \mathrm{MPa}$ \\
Minimum control tensioning strain & $f_{\min } / E=1,775 /(220 \times 10 e 3)=0.008068$ \\
Minimum control tension & $F_{\min }=f_{\min } \times A_{f}=1,775 \times 12=21300 \mathrm{~N}=21.3 \mathrm{kN}$ \\
Maximum control tensioning stress & $f_{\max }=0.8 f_{y c}=0.8 \times 3,550=2,840 \mathrm{MPa}$ \\
Maximum control tensioning strain & $f_{\max } / E=2,840 /(220 \times 10 e 3)=0.012909$ \\
Maximum control tension & $F_{\max }=f_{\max } \times A_{f}=2,840 \times 12=34.08 \mathrm{kN}$ \\
\hline
\end{tabular}

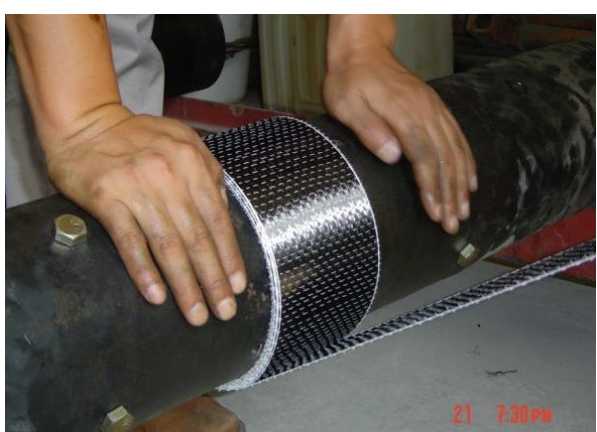

(a) Winding onto the rotating drum on one side

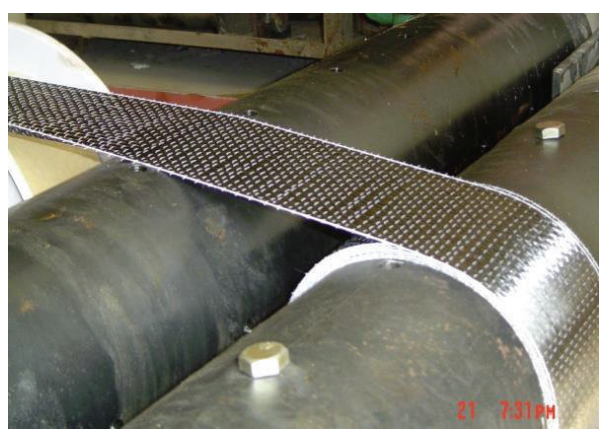

(c) Adjusting the position of the other rotating drum

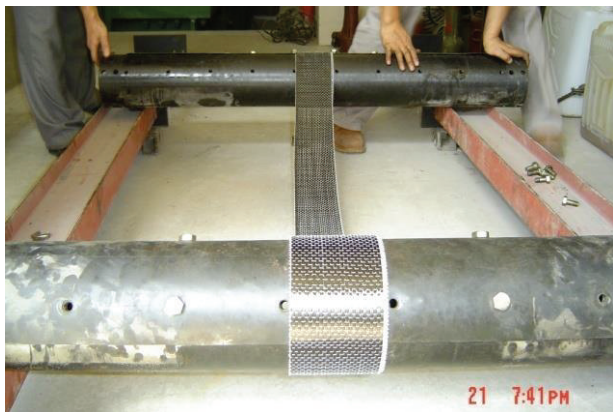

(e) Bidirectional winding before jack-up tensioning

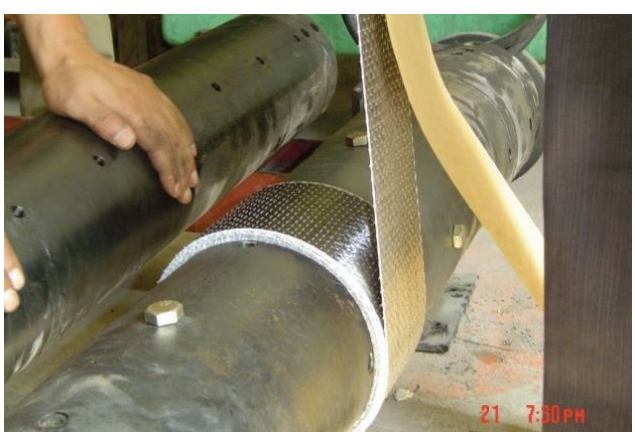

(b) Applying tension before unwinding

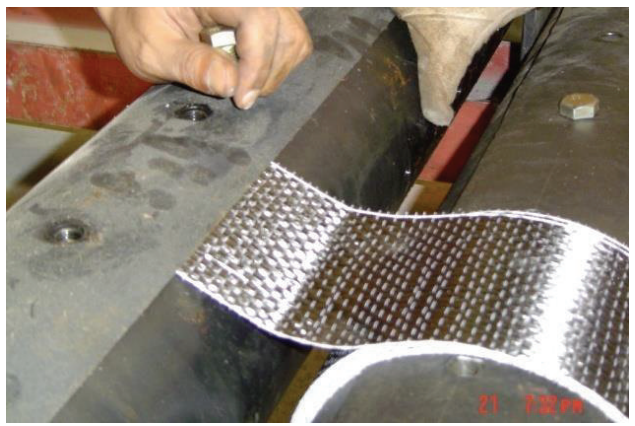

(d) Fixing the CFRP sheet using a clip

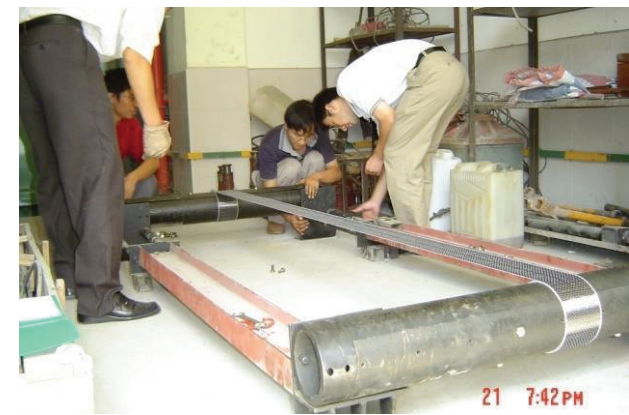

(f) Check-up on the fixation before the jack-up process

FIGURE 2: Jack-up tensioning process. 


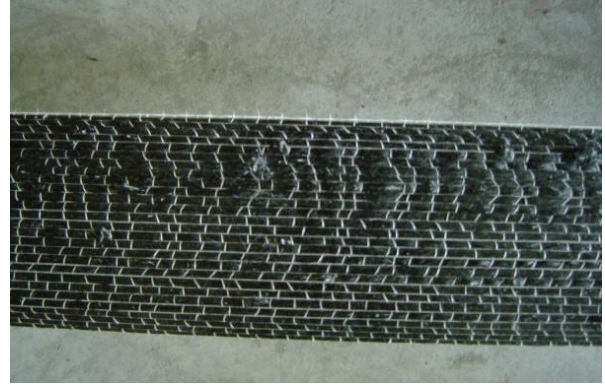

(a) Tensile failure from nonuniform tension

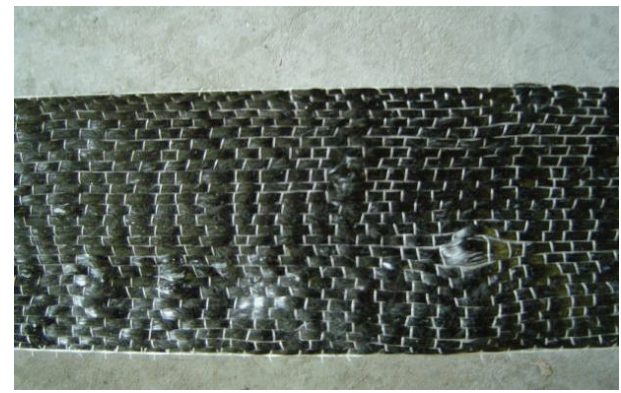

(b) Tensile failure from uniform tension

FIgURE 3: Different jack-up failure modes of the CFRP sheet.

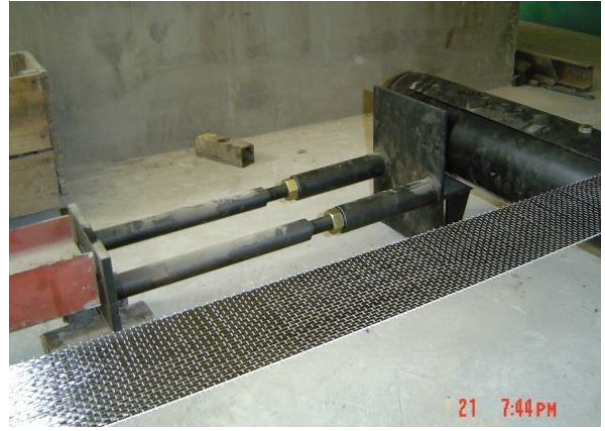

(a) After jack-up tensioning (the jacks are removed)

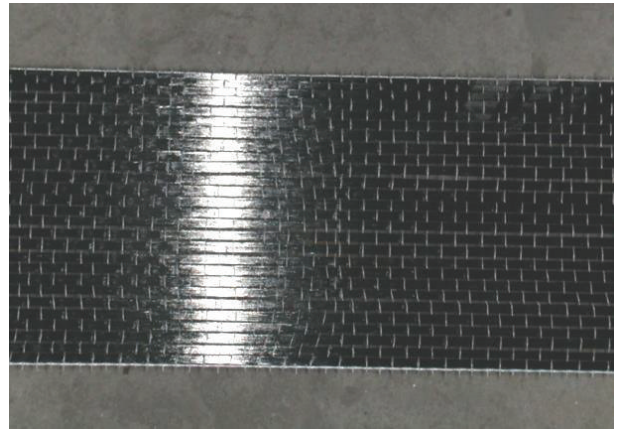

(b) Ideal tension effect

Figure 4: Ideal tension state of the CFRP sheet.

3.1.2. Applying Tension to Three CFRP Sheets Simultaneously. In practical applications, to simplify the construction procedure or to reduce the required equipment, there are very few occasions in which a single CFRP sheet is used. Compared to a single CFRP sheet, it is more difficult to apply tension to three CFRP sheets simultaneously because it is necessary to maintain uniform tension on all three CFRP sheets and to ensure the uniformity of the tension on each of the three CFRP sheets. Based on the experience gained from the tensioning of a single CFRP sheet and through continuous attempts, the final tensioning test was completed. Figure 5 shows the jack-up end and the anchorage end during the tensioning process.

To ensure that the prestress reaches the expected value in the concrete flat slab test, $0.17 \mathrm{~mm}$ thick CFRP sheets are used in the experiment. Through trial and error using the method described above, the final maximum jack-up force is $134 \mathrm{kN}$. The mean tensioning stress on each sheet is $2,627 \mathrm{MPa}$, which is approximately 0.74 times that of the tensile strength, whereas the tensioning stress on the sheet is 0.9 times that of the tensile strength when a single sheet is used, which warrants attention in practical application.

\subsection{Mechanical Properties of the Concrete Flat Slab Prestressed with CFRP Sheets}

3.2.1. Experimental Scheme and Design. To verify the feasibility of the proposed method and the practical effect of the application of prestress, the actual situation in which concrete slab structures are prestressed with CFRP sheets is tested. To date, there have been no related experimental studies on directly prestressing concrete structures with CFRP sheets. Therefore, the experimental study on prestressing concrete flat slabs with CFRP sheets is an exploratory study. A comparative experiment is also conducted; that is, results from an ordinary RC flat slab, CFRP sheet prestressed RC flat slab, and a CFRP sheet prestressed concrete flat slab are compared.

The slab is $2100 \mathrm{~mm}$ long, $600 \mathrm{~mm}$ wide, and $80 \mathrm{~mm}$ high with $1800 \mathrm{~mm}$ calculation span. The design live load $\left(q_{k}\right)$ is $15 \mathrm{kN} / \mathrm{m}^{2}$. C50 concrete is used $\left(f_{\mathrm{cm}}=26 \mathrm{MPa}\right.$ and $\left.f_{y}=210 \mathrm{MPa}\right)$. The concrete has a deadweight $(\gamma)$ of $23 \mathrm{kN} / \mathrm{m}^{3}$. The reinforcement design for the simply supported plate is performed according to the Design Specification for Reinforcement Concrete Structures. In addition, $\phi 6 / \phi 10 @ 95$ ( $4 \phi 6$ and $3 \phi 10)$ were selected, and a total of 128\$6@120 were used as the distribution steel bars. Figure 6 shows the reinforcement drawing.

Three $100 \mathrm{~mm}$ wide CFRP sheets were placed within the range of $b=600 \mathrm{~mm}$, and each CFRP sheet had a tensile strength $\left(f_{y c}\right)$ of 3,550 MPa. Lacking a proper design reference, the CFRP sheets are designed to be tensioned based on $50 \%$ of the tensile strength. It is assumed that the CFRP sheet reaches $70 \%$ of its tensile strength at failure. The flexural design for the simply supported plate is performed again according to the Design Specification for Reinforcement Concrete Structures. The stresses on the upper and lower 


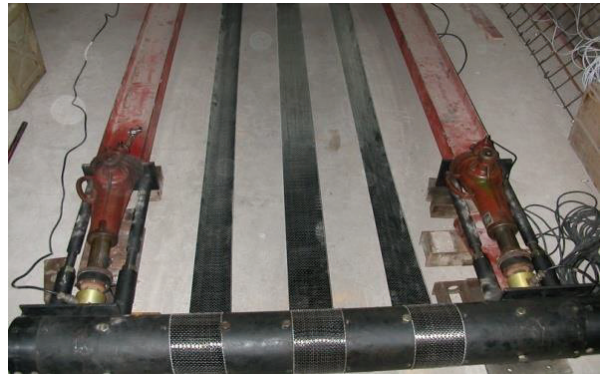

(a) Winding of CFRP sheets at the jack-up end

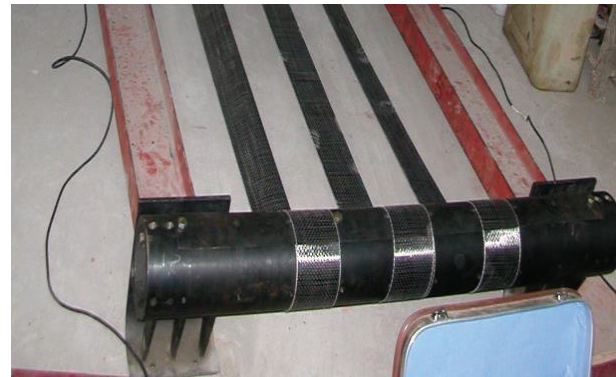

(b) Winding of the CFRP sheets at the anchorage end

FIGURE 5: Photographs of the jack-up tensioning of multiple CFRP sheets.

Force-bearing bars $\phi 6 @ 190$ Force-bearing bars $\phi 10 @ 190 \quad$ Distribution steel bars $\phi 6 @ 120$
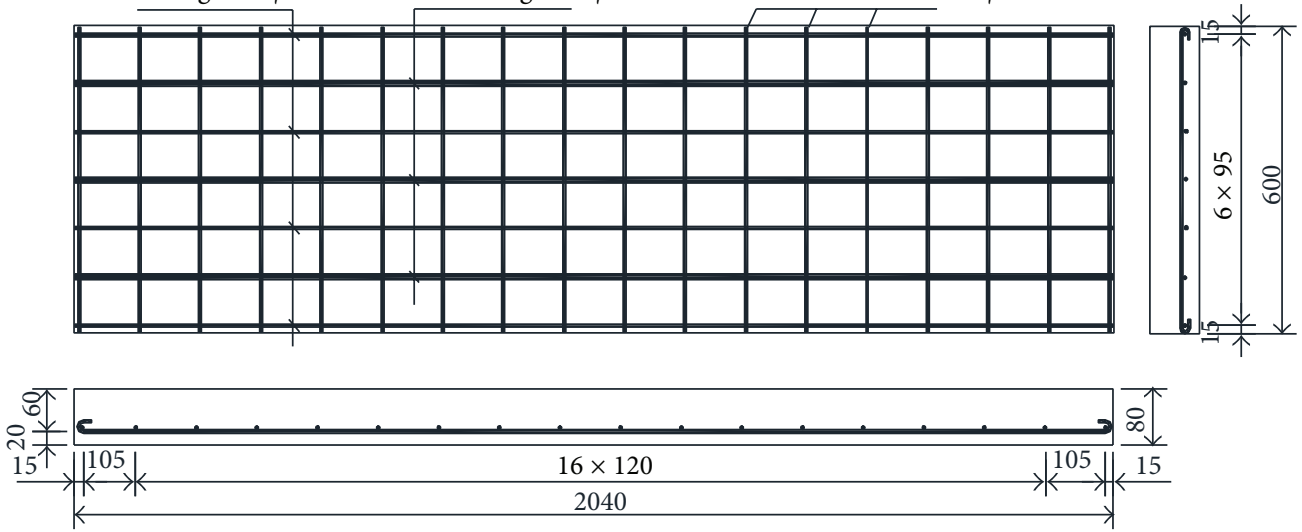

FIgure 6: Construction drawing of the ordinary RC slab.

edges of the cross section of the concrete are calculated to be $0.53 \mathrm{MPa}$ and $-5.45 \mathrm{MPa}$, respectively.

Considering the disadvantages of cracks caused by full prestressing, for example, excessively fast development and poor structural ductility, some ordinary steel bars are added to the fully CFRP prestressed concrete slab to study the effect of ordinary steel bars on the CFRP prestressed structure. Considering the positions of steel bars limited by the actual layout of the CFRP sheets, 4\$6@190 are only added to the gaps among the CFRP sheets based on the CFRP sheet prestressed flat slab; that is, one steel bar is placed in each of the gaps among the three CFRP sheets (Figure 7).

3.2.2. Construction of the Prestressed Concrete Flat Slabs. A flat slab is poured at the Structure Laboratory in the Department of Bridge Engineering at Tongji University. The following steps are used in the construction:

(1) The $20 \mathrm{~mm}$ thick bottom of the concrete is poured (Figure 8(a)), vibrated (Figure 8(b)), and levelled (Figure 8(c)).

(2) The anchoring device is jacked up, and tension is applied to the CFRP sheets.

(3) The $60 \mathrm{~mm}$ thick top layer of the concrete is poured and levelled.

The jack-up tensioning is controlled based on the pressure measured at the end of the jack. The tension design control force is $N=0.65 f_{y c} A_{P}=1.18 \times 10^{5} \mathrm{~N}$; however, when stabilized, the readings indicate that the jack-up forces on the two sides are $55 \mathrm{kN}$ and $53 \mathrm{kN}$. After the concrete is poured, the readings show that the jack-up forces further decrease to $39 \mathrm{kN}$ and $42 \mathrm{kN}$. The calculation shows that only $44.6 \%$ of the tensile strength of the CFRP sheets is reached.

When pouring the top layer of the concrete, the CFRP sheets must be protected from damage caused by the tension. During the pouring process, a spacing of $100 \mathrm{~mm}$ between two CFRP sheets is shown to be unfavourable to the vibration of the concrete; that is, the concrete vibrator can only move in a $100 \mathrm{~mm}$ wide gap, which affects the construction speed and is detrimental to the construction quality. That is, the vibrator could easily destroy the fibres in the CFRP sheets during the vibration process. Figures 8 (c) and 8 (d) show the situation in which the surface of the concrete slab is treated as well as the final curing condition of the concrete slab, respectively.

3.2.3. Experimental Testing and Results. An evenly distributed load is applied to the flat slab. However, considering the convenience of the experimental operation and the conditions set in the laboratory, the common loading mode for bending-resistant components is used when loading the one-way slab in practice. The three-dividing-point loading method (Figure 9) is used to compare the flexural performance of the ordinary RC slab and the CFRP prestressed RC slab. Figure 10 shows the actual loading process. 


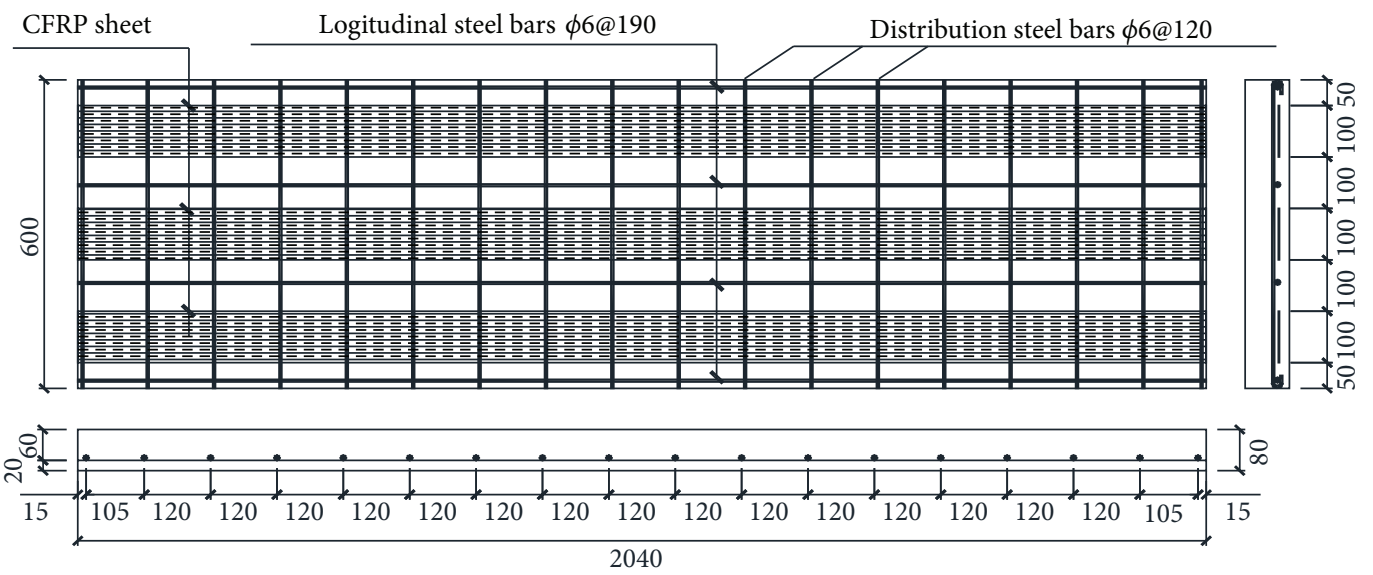

FIGURE 7: Construction layout of the CFRP sheet prestressed concrete slab (unit: $\mathrm{mm}$ ).

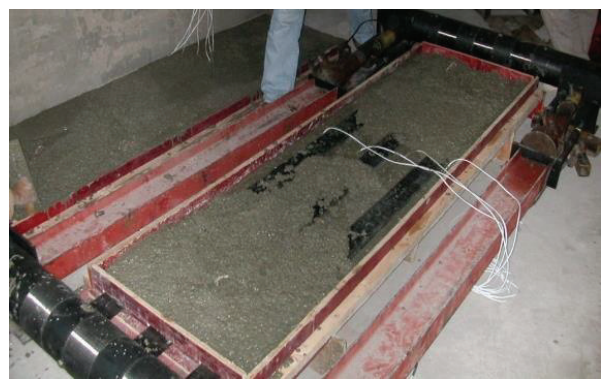

(a) Pouring concrete

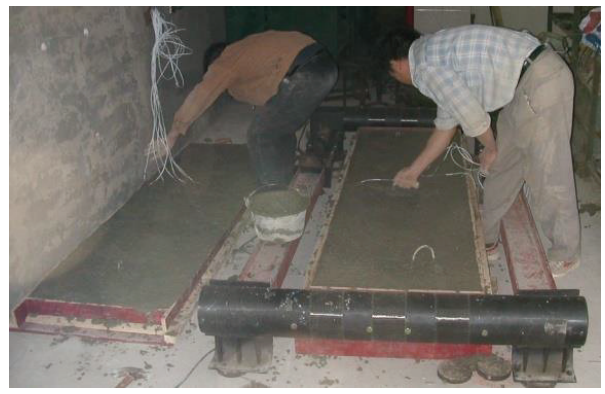

(c) Levelling concrete

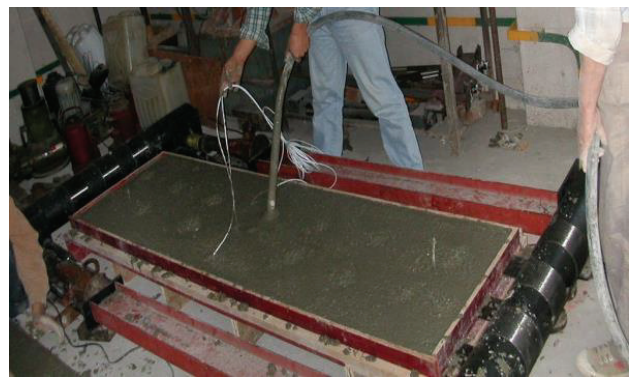

(b) Vibrating concrete

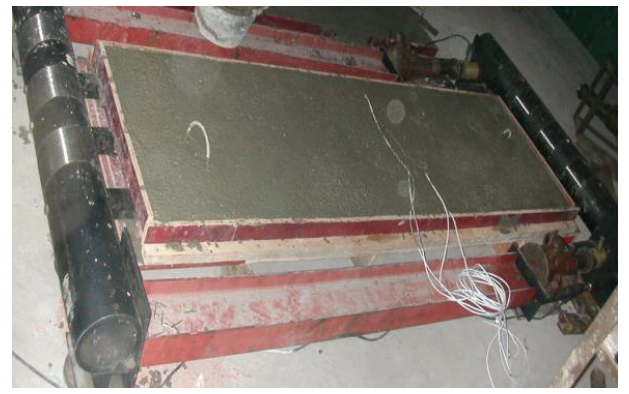

(d) Curing concrete

FIGURE 8: Construction process of the concrete slab.

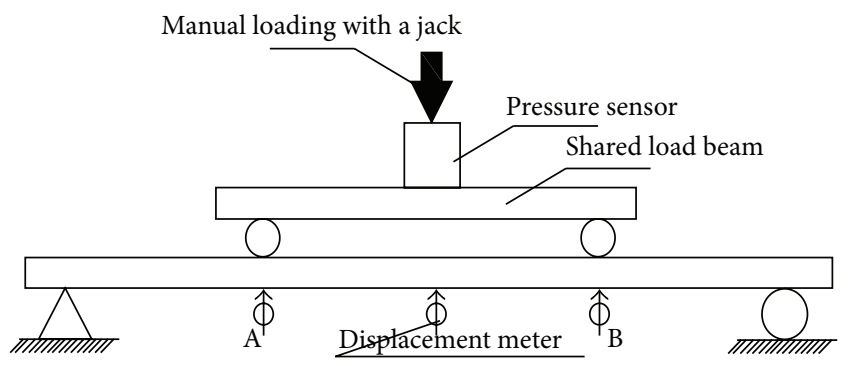

FIGURE 9: Schematic of the three-dividing-point loading process.

To obtain the mechanical properties of the concrete slab during the loading process, concrete strain gauges are attached to the roof and the bottom of the concrete slab at the midspan section and at the locations of the force-bearing steel bars. Figure 11 shows the corresponding measuring points. The concrete strain gauges on the CFRP prestressed flat slab correspond to the locations of the longitudinal steel bars in the ordinary concrete slab.

Figure 12 shows a comparison between the midspan deflection curves of the RC slab and the CFRP prestressed slab. The data in Figure 12 show that the cracking load of the RC slab is insignificant, whereas the cracking load of the CFRP slab is approximately $15 \mathrm{kN}$, and the deflection increases rapidly after the slab is cracked. Figure 13 shows the corresponding strain curves of concrete and steel bars at the midspan cross section.

In terms of the ultimate bearing capacity, the designed CFRP prestressed slab does not reach the expected load value, 


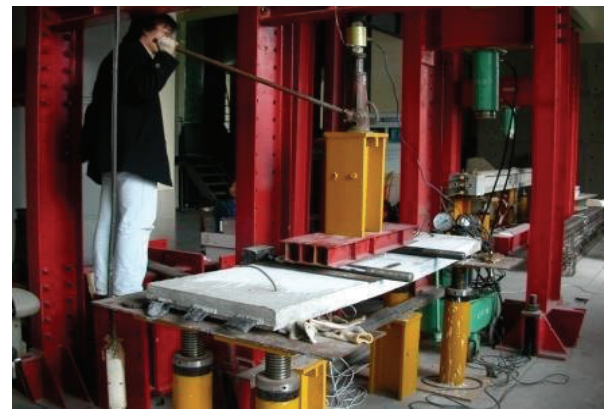

Figure 10: Photograph of the loading process.

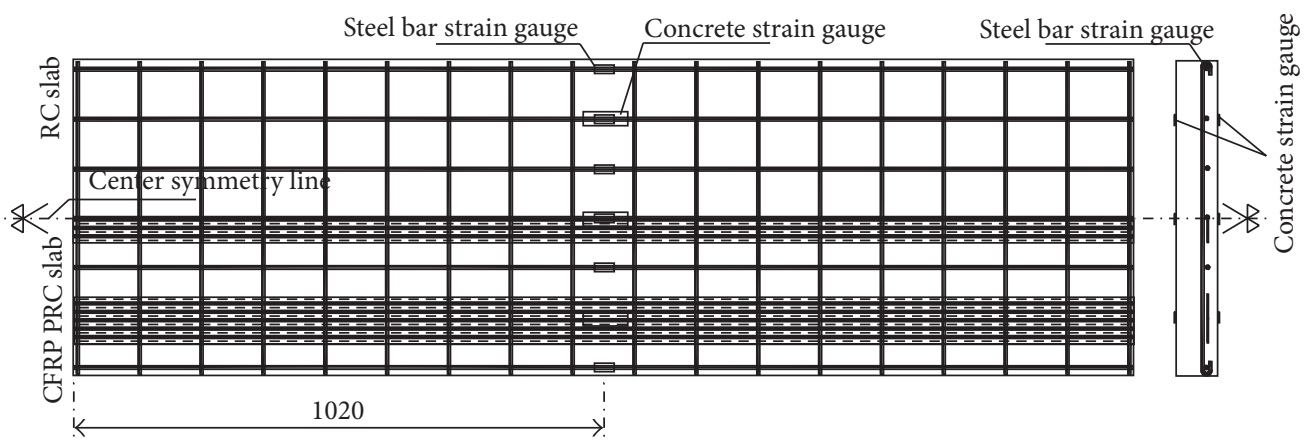

FIGURE 11: Layout of the measuring points on the RC slab and CFRP PRC slab. Note. A total of seven steel bar strain gauges and a total of six concrete strain gauges (three gauges on the bottom of the slab and three gauges on the top of the slab).

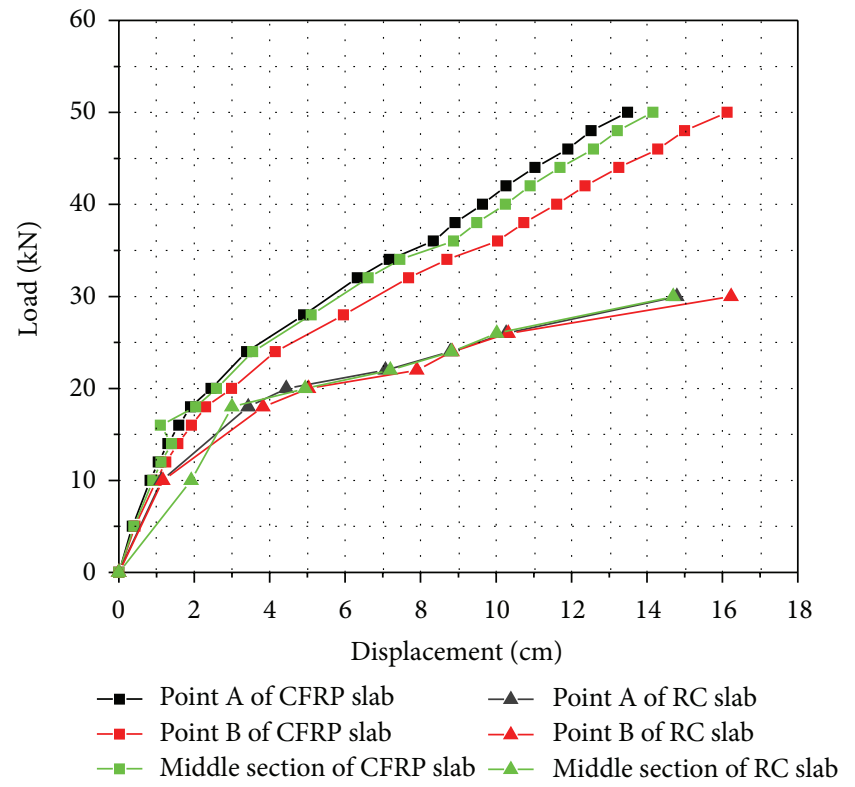

FIgURE 12: Deflection-load curves for the RC slab and the CFRP slab.

primarily because of the prestress loss and the maximum development of cracks. Because the effective prestress of the CFRP prestressed slab was relatively low, the cracking load of the CFRP prestressed slab is nearly the same as that for the RC slab. However, because ordinary steel bars inhibit and disperse the development of cracks, the ultimate bearing capacity of ordinary steel bars is greater than the prestress of the CFRP prestressed slab.

\section{Analysis}

Although 0.9 times tensile strength can be reached for a single CFRP sheet, the verified tests proved that the mean tensioning strength is only about 0.75 times that of the tensile strength. So about 0.7 times tensile strength is more possible for practice. Further experimentation is required to determine whether a higher tensioning stress can be reached when multiple sheets are used.

Several methods that can be used to improve the uniformity of the tension on three sheets are summarized below:

(1) Ensure that the winding lengths of the three CFRP sheets are the same.

(2) Improve the accuracy of the initial cutting length.

(3) Complete the fixing and winding of the three sheets at the same time.

(4) Use a winding method with guide rails to allow one rotating drum to rotate along the guide rails in the parallel way as the other rotating drum to ensure that the two rotating drums are parallel.

The experiment on the CFRP prestressed slab that contained no steel bars was not performed; therefore, because there is a larger contact area between the CFRP sheet and the concrete, further studies are necessary to understand 


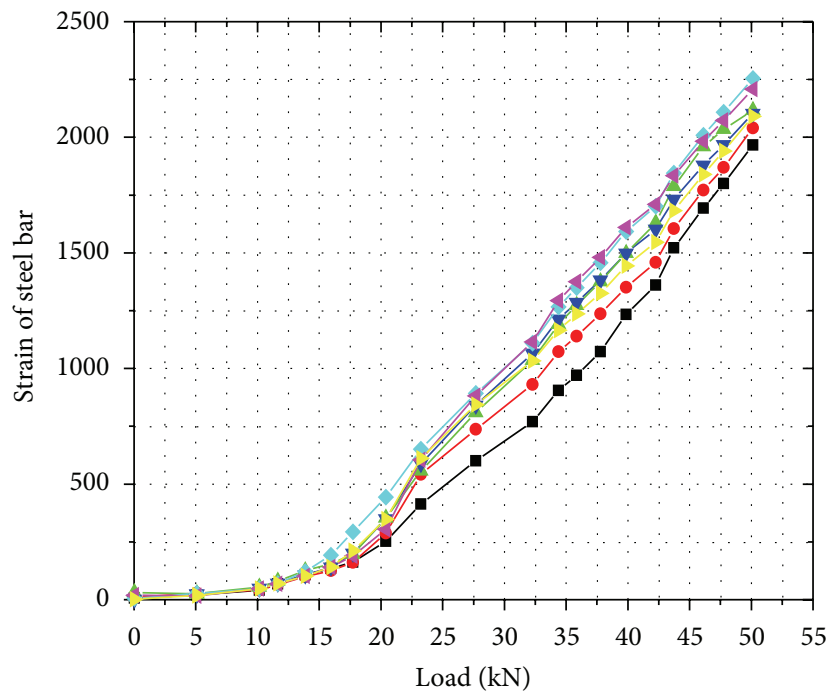

(a) Strain curve of the ordinary steel bars in the RC slab

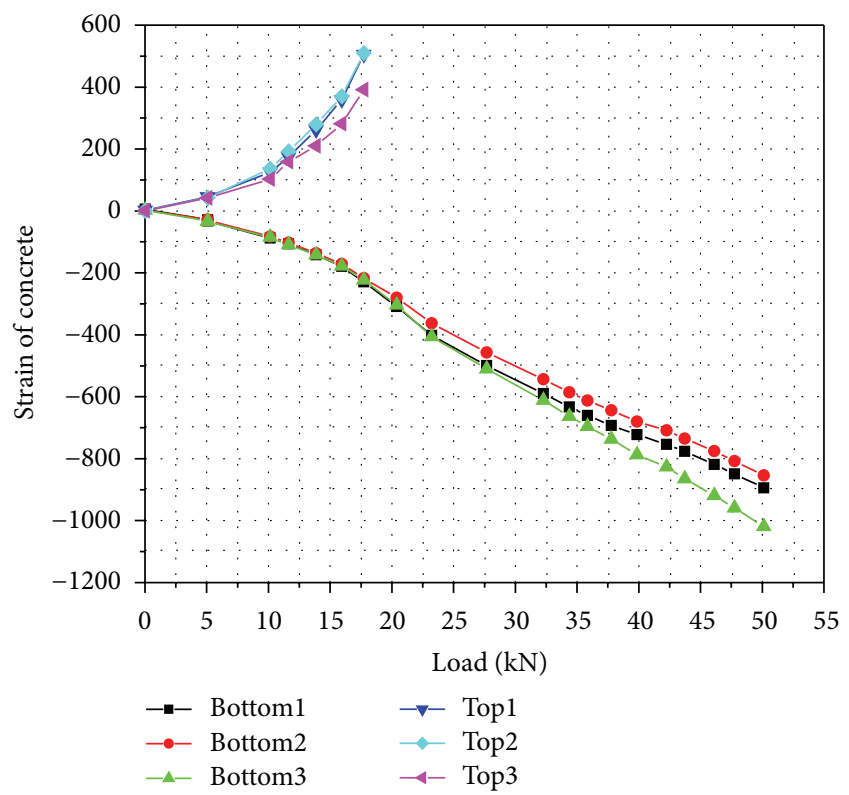

(c) Strain curve of the concrete in the RC slab

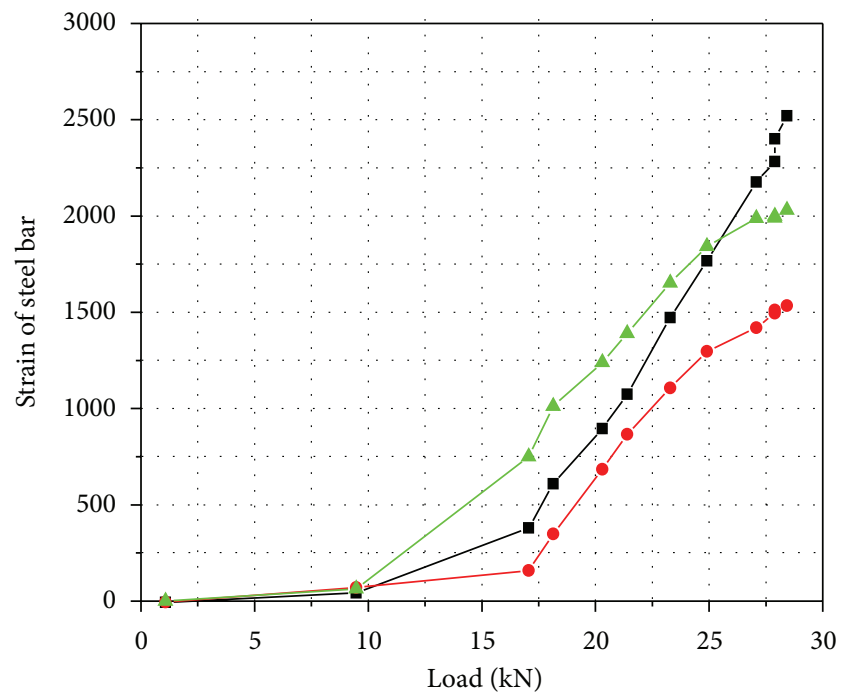

(b) Strain curve of the steel bars in the CFRP slab

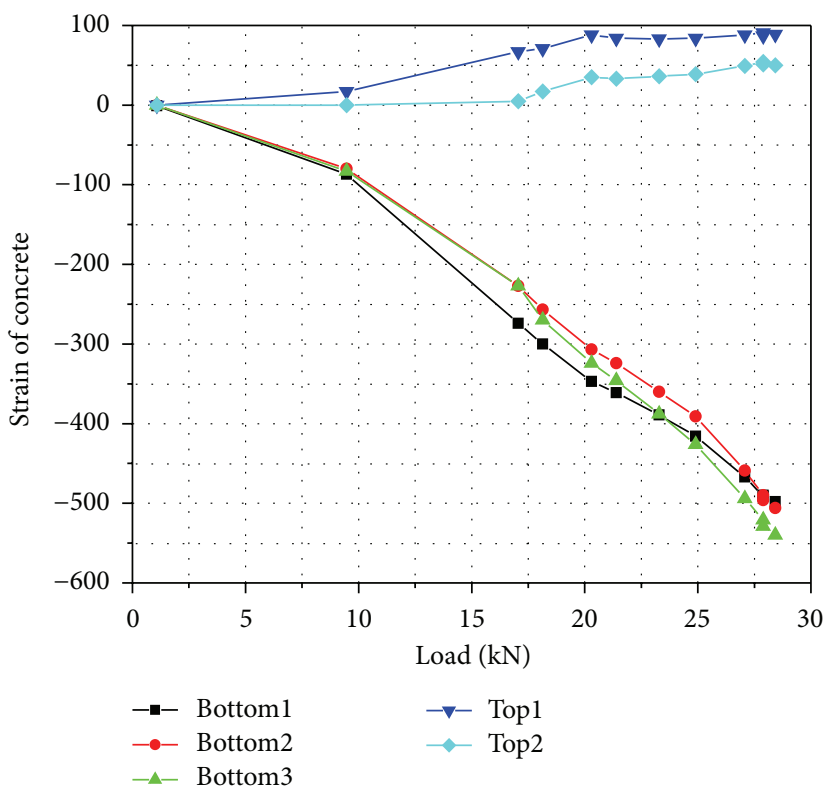

(d) Strain curve of the concrete in the CFRP slab

FIGURE 13: Strain curves of the concrete and the steel bars at the midspan cross section.

the effect of the CFRP sheet on inhibiting and dispersing cracks. A possible reason for the rapid dispersion of cracks is the following. The stress on the CFRP sheet is nonuniform, resulting in the premature failure of the CFRP fibres, which in turn results in rapid structural damage.

The experimental results indicate that there is no difference in the use of the structure other than the ordinary steel bars being replaced by the CFRP sheets; however, the cracking load remains the same or even increases, and the ultimate bearing capacity changes. The CFRP prestressed slab is more advantageous based on the comparison between the routine service stages of the two slabs. Structurally, the CFRP sheets have a smaller deadweight, and the cracking load of the CFRP sheets remains the same or even increases. Additionally, the durability of the CFRP sheets is more favourable to the service life of the structure. Further cost comparisons must be based on the specific engineering application.

\section{Conclusions}

(1) Prestress was applied using a CFRP sheet material that had been tensioned using a winding process. The shearing of an anchoring device that uses clips was avoided by using the prestressing method; therefore, the possibility of the shear failure of fibres was reduced. The CFRP sheet material was prestressed using the fabricated jack-up tensioning device.

(2) When applying uniform tension, the tensioning strength was ensured to reach $3,160 \mathrm{MPa}$, which was $90 \%$ of the tensile strength of the material; otherwise, 
the tensioning strength was only $2,027 \mathrm{MPa}$, which was $60 \%$ of the tensile strength of the material. It was more difficult to uniformly tension multiple CFRP sheets simultaneously than to do so for one single CFRP sheet. When multiple CFRP sheets were tensioned simultaneously, the mean tensioning stress on each CFRP sheet was only 2,627 MPa, which was approximately $74 \%$ of the tensile strength of the material.

(3) The uniformity of the stress on the fibres in the CFRP sheet could be improved through adjusting the initial cutting length and the jack-up speeds on both sides and improving the precision of the parallel winding. Because of the nonuniformity of the jackup tensioning method, there is a design limit for the tensioning control stress of the CFRP sheet.

(4) The monitoring data obtained from the sensor during the concrete pouring process show that the stability of the jack-up frame significantly impacted the stress on the CFRP sheet. Additionally, the monitoring data show that the stress loss of the CFRP sheet was relatively significant. Further studies are necessary to understand the cause for this stress loss.

(5) Based on the development of cracks in the slab partially prestressed with CFRP sheets, it was concluded that the prestressing effect was still effective. It could be seen from the distribution and development patterns of cracks in the RC slab and the CFRP sheet prestressed slab that the CFRP prestressed slab might still need ordinary steel bars to inhibit and disperse the development of cracks and avoid the excessive concentration of cracks and the occurrence of large cracks to avoid the occurrence of brittle failure.

(6) The relatively low ultimate bearing capacity of the CFRP sheet prestressed slab might be related to the nonuniform stress on the CFRP sheets and the prestress loss that occurred at a later stage. Further studies are needed to search for a method that can be used to apply a more effective prestress.

\section{Conflict of Interests}

The authors declare that there is no conflict of interests regarding the publication of this paper.

\section{References}

[1] S. Pimenta and S. T. Pinho, "Recycling carbon fibre reinforced polymers for structural applications: technology review and market outlook," Waste Management, vol. 31, no. 2, pp. 378-392, 2011.

[2] L. C. Hollaway, "A review of the present and future utilisation of FRP composites in the civil infrastructure with reference to their important in-service properties," Construction and Building Materials, vol. 24, no. 12, pp. 2419-2445, 2010.
[3] J. Jayaprakash, E. Pournasiri, K. K. Choong, C. G. Tan, and F. De'Nan, "External CFRP repairing of pretested beams reinforced using prestress rebars," Journal of Reinforced Plastics and Composites, vol. 30, no. 20, pp. 1753-1768, 2011.

[4] N. Wahab, T. Topper, and K. A. Soudki, "Modelling experimental bond fatigue failures of concrete beams strengthened with NSM CFRP rods," Composites Part B: Engineering, vol. 70, pp. 113-121, 2015.

[5] M. Rezazadeh, I. Costa, and J. Barros, "Influence of prestress level on NSM CFRP laminates for the flexural strengthening of RC beams," Composite Structures, vol. 116, no. 1, pp. 489-500, 2014.

[6] P. Nabipay and D. Svecova, "Shear behavior of CFRP prestressed concrete T-beams," Journal of Composites for Construction, vol. 18, no. 2, Article ID 04013049, 2014.

[7] M. M. Önal, "Strengthening reinforced concrete beams with CFRP and GFRP," Advances in Materials Science and Engineering, vol. 2014, Article ID 967964, 8 pages, 2014.

[8] H. D. Yapa and J. M. Lees, "Rectangular reinforced concrete beams strengthened with CFRP straps," Journal of Composites for Construction, vol. 18, no. 1, 2014.

[9] S. M. Mosavi and A. S. Nik, "Strengthening of steel-concrete composite girders using carbon fibre reinforced polymer (CFRP) plates," Sadhana: Academy Proceedings in Engineering Sciences, vol. 40, no. 1, pp. 249-261, 2015.

[10] National Industrial Building Diagnosis and Retrofit Engineering Technology Research Centre of China, Technical Specification for Strengthening Concrete Structures with Carbon Fibre Reinforced Polymer Laminate, China Planning Press, Beijing, China, 2007.

[11] A. Mostafa and A. G. Razaqpur, "CFRP anchor for preventing premature debonding of externally bonded FRP laminates from concrete," Journal of Composites for Construction, vol. 17, no. 5, pp. 641-650, 2013.

[12] A. A. B. Mostafa and A. G. Razaqpur, "A new CFRP anchor for preventing separation of externally bonded laminates from concrete," Journal of Reinforced Plastics and Composites, vol. 32, no. 24, pp. 1895-1906, 2013.

[13] S. Ghasemi, A. A. Maghsoudi, H. A. Bengar, and H. R. Ronagh, "Flexural strengthening of continuous unbonded posttensioned concrete beams with end-anchored CFRP laminates," Structural Engineering and Mechanics, vol. 53, no. 6, pp. 10831104, 2015.

[14] Y. J. Kim, M. F. Green, and R. G. Wight, "Effect of prestress levels in prestressed CFRP laminates for strengthening prestressed concrete beams: a numerical parametric study," PCI Journal, vol. 55, no. 2, pp. 96-108, 2010.

[15] Y. Kim, K. Quinn, W. M. Ghannoum, and J. O. Jirsa, "Strengthening of reinforced concrete T-beams using anchored CFRP materials," ACI Structural Journal, vol. 111, no. 5, pp. 1027-1036, 2014.

[16] J. Michels, E. Martinelli, C. Czaderski, and M. Motavalli, "Prestressed CFRP strips with gradient anchorage for structural concrete retrofitting: experiments and numerical modeling," Polymers, vol. 6, no. 1, pp. 114-131, 2014.

[17] M. Q. Zhu, H. Pan, F. J. Wei, and Q. Liu, "An experimental study and analysis of full process of external prestressing CFRP concrete box girder," Applied Mechanics and Materials, vol. 351352, pp. 1008-1013, 2013. 
[18] G. Şakar and H. M. Tanarslan, "Prestressed CFRP fabrics for flexural strengthening of concrete beams with an easy prestressing technique," Mechanics of Composite Materials, vol. 50, no. 4, pp. 537-542, 2014.

[19] W. Sun and W. M. Ghannoum, "Modeling of anchored CFRP strips bonded to concrete," Construction and Building Materials, vol. 85, pp. 144-156, 2015. 

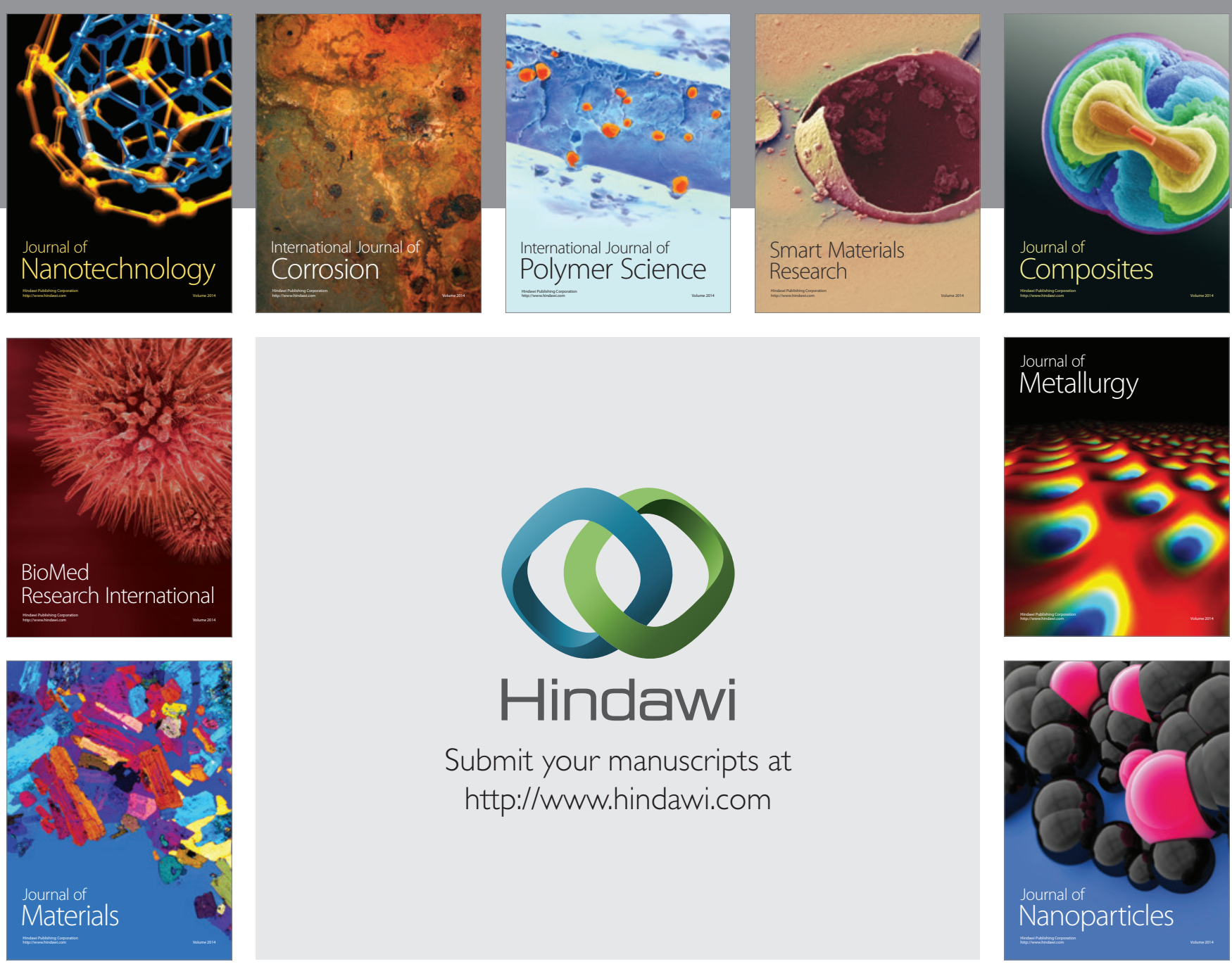

Submit your manuscripts at http://www.hindawi.com
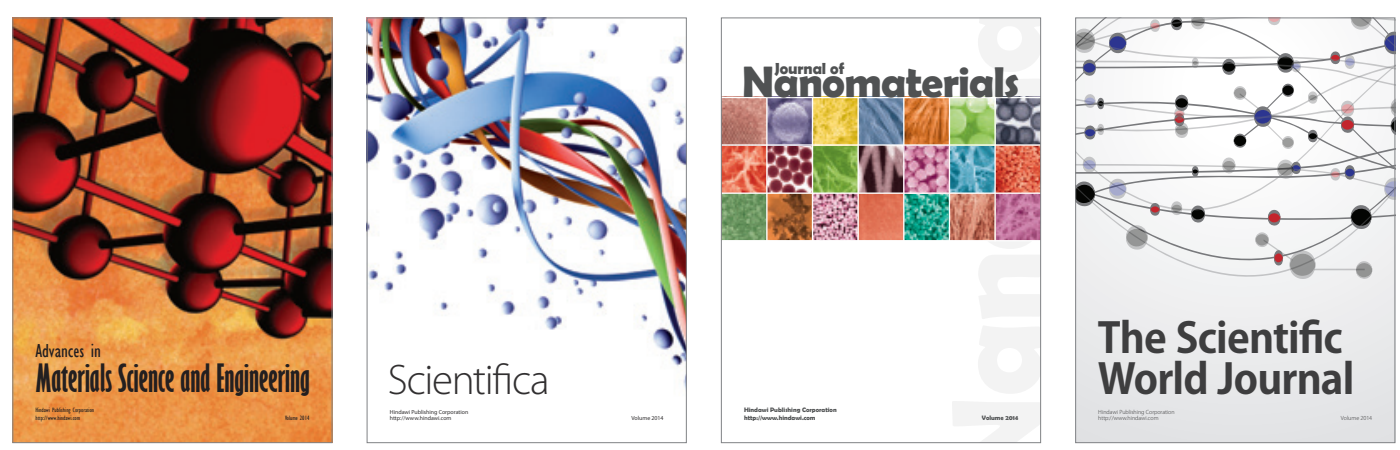

\section{The Scientific World Journal}
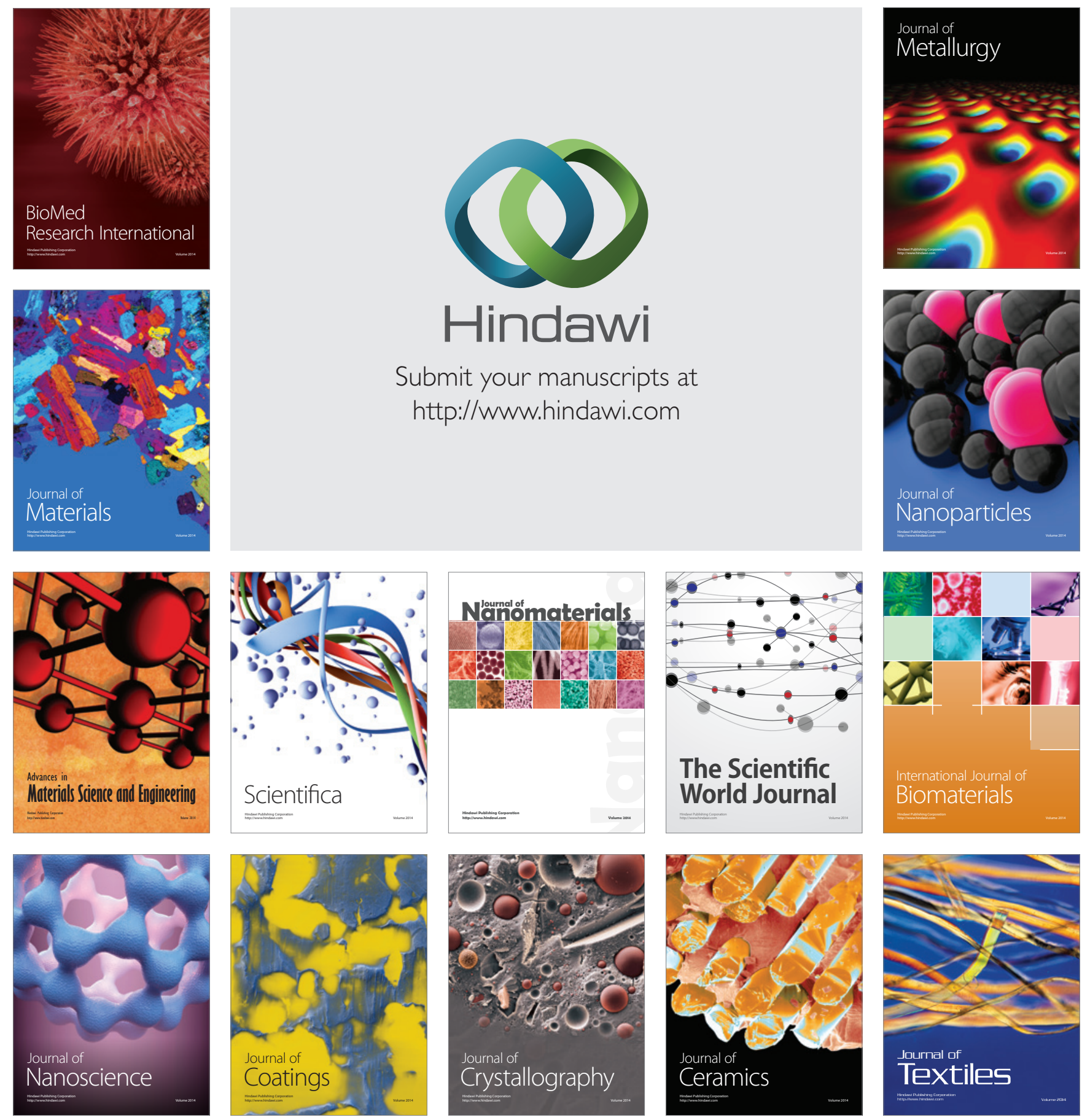